\title{
ASSOCIAÇÃO DA RELAÇÃO ENTRE OS PREÇOS DE FRETES DE SOJA E DO ÓLEO DIESEL NO PERÍODO DE 2015 A $2018^{1}$
}

\section{ASSOCIATION OF THE RELATIONSHIP BETWEEN THE PRICES OF SOYBEANS AND DIESEL OIL IN THE PERIOD FROM 2015 TO 2018}

\section{Recebimento: 29/08/2018 - Aceite: 28/06/2019 - Publicação: 31/07/2019 \\ Processo de Avaliação: Double Blind Review}

\author{
Amanda Cristina Gaban Filippi ${ }^{2}$ \\ Doutoranda em Agronegócios pela Universidade Federal de Goiás \\ Mestre em Agronegócios pela Universidade de Brasília \\ amandagaban@hotmail.com
}

Reginaldo Santana Figueiredo

Professor do Programa de Pós-Graduação em Agronegócio da Universidade Federal de Goiás

Doutor em Economia de Indústria pela Universidade Federal do Rio de Janeiro emaildesantana@gmail.com

\section{RESUMO}

O objetivo desse trabalho foi analisar as relações entre os preços de fretes de soja e preços do óleo diesel da cidade de Sorriso/MT até o porto de Santos/SP, no período de janeiro de 2015 a maio de 2018. Para tanto, foram determinadas e analisadas as relações entre as variáveis preço de frete de soja e preço do óleo diesel por meio do diagrama de dispersão, correlação e regressão linear. Os principais resultados indicam que existe baixa correlação linear positiva entre frete de soja e preço do diesel, portanto, o preço do óleo diesel influencia pouco o frete de soja para o período e rota estudados, sendo

\footnotetext{
${ }^{1}$ Os autores agradecem ao Instituto Matogrossense de Economia Aplicada (IMEA) pela disponibilização dos dados referentes aos fretes agrícolas de soja e a Agência Nacional do Petróleo, Gás Natural e Biocombustíveis (ANP) pela disponibilização dos dados referentes aos valores de óleo diesel.

${ }^{2}$ Autor para correspondência: Universidade Federal de Goiás. Avenida Esperança, s/n.. Setor de Desenvolvimento Rural, Goiânia-GO, Brasil. CEP: 74.690-900.
} 


\section{REVISTA ENIAC PESQUISA}

que outros fatores como oferta e demanda, sazonalidade, disponibilidade de armazenagem, greves, condições de infraestrutura, distância origem/destino, porto exportador, carga de retorno e etc. também afetam o preço do frete de soja.

Palavras-Chave: Logística de Distribuição, Fretes de Soja, Preço diesel, Relações lineares; Agronegócio.

\section{ABSTRACT}

The aim of this study was to analyze the relationship between soybean freight prices and diesel oil prices for the city of Sorriso/MT up to the port of Santos, from January 2015 to May 2018. The relationships between the variables soybean freight price and diesel oil price were analyzed through the dispersion, correlation and linear regression diagram. The main results indicate that there is a low positive linear correlation between soybean freight and diesel price, and therefore, the price of diesel oil has little influence on soybean freight for the period and route studied, and other factors such as supply and demand, seasonality, warehouse availability, strikes, infrastructure conditions, origin/destination distance, export port, return cargo and etc, also affect the price of soybean freight.

Keywords: Distribution Logistics, Soybean Freight, Diesel Price, Linear Relationships; Agribusiness.

\section{INTRODUÇÃO}

O Brasil é um dos principais produtores e exportadores de soja, sendo que os produtos agrícolas auxiliam o crescimento e desenvolvimento do país. Contudo, a Logística de Distribuição do Agronegócio, em sua atividade de transporte, ainda é ineficiente e apresenta diversas barreiras e problemas para o escoamento (COTRIM; MACHADO, 2011; FILIPPI, 2017). Tal fato gera custos desnecessários para toda cadeia produtiva e perda de competitividade e de mercado externo do Agronegócio Brasileiro (SOARES; CAIXETA FILHO, 1997; OLIVEIRA, 2011; OLIVEIRA; CICOLIN; SANTOS, 2014). 
Dentre os gargalos logísticos da atividade de transporte, quanto ao escoamento de commodities agrícolas (SOARES; CAIXETA FILHO, 1997; CORREA; RAMOS, 2010), destacam-se o uso predominante e indevido da modalidade rodoviária no país da qual o frete é um dos principais componentes (CAIXETA-FILHO; GAMEIRO, 2001) e a influência de diversos fatores como a infraestrutura precária, estado precário das estradas, gastos com combustíveis, eficiência do porto exportador, disponibilidade de armazenagem, não uso da intermodalidade, sazonalidade, carga de retorno, especificidades da carga e do veículo, prazo e tempo de entrega, pedágios e fiscalização e falta de ferrovias no território (CORREAA JUNIOR; CAIXETA FILHO, 2003; MARTINS, 2008; CAIXETA FILHO; MARTINS, 2011; CANGUSSU; ROSA; FIGUEIREDO, 2013).

O objetivo desse trabalho é analisar as relações entre os preços de fretes de soja e preços do óleo diesel para a rota da cidade de Sorriso no Estado do Mato Grosso até o porto de Santos, no período de janeiro de 2015 a maio de 2018.

Os principais resultados indicam baixa influência do preço do diesel em relação ao frete de soja para a rota e período do estudo. Ademais, outros fatores podem influenciar o valor do frete como oferta e demanda, greves, condições de infraestrutura e distância origem/destino.

\section{LOGÍSTICA DE DISTRIBUIÇÃO E AGRONEGÓCIO DA SOJA}

O Brasil é um dos principais produtores e exportadores de grãos, com destaque para a região Centro-Oeste, principal região produtora de grãos do país, e o estado do Mato Grosso, principal estado produtor de soja com representatividade de 27,26\% da produção nacional da commodity (COMPANHIA NACIONAL DE ABASTECIMENTO [CONAB], 2018; GABAN et al., 2017) (Tabela 1).

Tabela 1 - Previsão da Produção de Soja, safra 2017/18.

\begin{tabular}{lcc}
\hline REGIÃO/UF & 2017/18 Previsão (1) & Representatividade (\%) \\
\hline CENTRO-OESTE & $53.282,8$ & $45,54 \%$ \\
${ }^{*}$ MT & $31.887,3$ & $27,26 \%$ \\
SUL & $38.343,7$ & $32,77 \%$ \\
NORDESTE & $10.716,8$ & $9,16 \%$ \\
SUDESTE & $8.778,8$ & $7,50 \%$ \\
NORTE & $5.873,8$ & $5,02 \%$ \\
\hline BRASIL & $116.995,9$ & $100 \%$ \\
\hline \multicolumn{2}{c}{ Fonte: Adaptado de CONAB (2018). $\left.{ }^{1}{ }^{1}\right)$ Em mil toneladas. }
\end{tabular}

Revista ENIAC Pesquisa, Guarulhos (SP), V.8, n.2, jul.- dez. 2019. 
Tais produtos, além de manterem a balança comercial com saldo positivo (MINISTÉRIO DA INDÚSTRIA, COMÉRCIO EXTERIOR E SERVIÇOS [MDCI], 2018), são importantes para a geração de crescimento e desenvolvimento do país (GABAN et al., 2017). Entretanto, a logística de distribuição, em sua atividade de transporte, apresenta problemas logísticos que comprometem negativamente $\mathrm{o}$ desempenho do escoamento dos produtos agrícolas no país (COTRIM; MACHADO, 2011; FILIPPI, 2017). Tal fato causa perda de competitividade e de mercado externo do Agronegócio Brasileiro e gera custos desnecessários para a cadeia produtiva como um todo (SOARES; CAIXETA FILHO, 1997; OLIVEIRA, 2011; OLIVEIRA; CICOLIN; SANTOS, 2014).

Um desses problemas logísticos relacionados à atividade do transporte é a predominância e uso indevido do modal rodoviário para o transporte de commodities agrícolas (SOARES; CAIXETA FILHO, 1997; CORREA; RAMOS, 2010), como é o caso da soja. A modalidade de transporte rodoviária representa em torno de 61,1\% na matriz de transporte do país (CONFEDERAÇÃO NACIONAL DO TRANSPORTE [CNT], 2018) e tem custos variáveis altos, o que encarece o produto. Além disso, essa não é a modalidade mais recomendada para commodities, que são produtos de baixo valor agregado (SOARES; CAIXETA FILHO, 1997; CORREA; RAMOS, 2010; MARTINS et al., 2014), que percorrem longas distâncias e apresentam volumes consideráveis (BALLOU, 2011), como no caso da região Centro-Oeste, até os principais portos exportadores, Santos e Paranaguá (FILIPPI; GUARNIERI; FARIAS, 2017).

Ademais, as estradas no país estão em estado precário, o que causa a perda física da soja durante o transporte e contribui com o aumento do preço do frete agrícola devido ao desgaste sofrido pelos caminhões (OLIVEIRA; CICOLIN; SANTOS, 2014). Resende, Bonjour e Figueiredo (2007) relatam que o sistema de transporte da soja é um dos pontos mais importantes em sua cadeia produtiva, já que os custos com transporte representam a maior parte dos custos do produto soja.

De acordo com Oliveira, Cicolin e Santos (2014), em se tratando de custos variáveis, as despesas com combustíveis, como o óleo diesel usado no transporte de soja, é o principal item, representando $46 \%$ do custo variável total. Soares e Caixeta 


\section{REVISTA ENIAC PESQUISA}

Filho (1997) relatam que o frete sempre sofrerá influência do preço do óleo diesel, sendo reajustado na mesma proporção, e que o frete se tornou $\mathrm{o}$ fator mais representativo dos custos finais de produtos agrícolas (CASTILLO, 2004), sendo que os custos com frete podem variar de 1/3 a 2/3 dos custos logísticos totais (SILVA et al., 2018).

Para Morales, D’Agosto e Souza (2013), uma solução para reduzir o custo alto do frete, como também driblar alguns gargalos logísticos, seria o escoamento da produção do norte do estado do Mato Grosso para o porto de Santarém (PA), ou seja, o escoamento pelo Arco Norte do país. Segundo os autores, o corredor reduziria em até 30 dólares por tonelada o valor do frete. Entretanto, a principal rodovia que integra esses locais, a BR-163, ainda não está totalmente pavimentada.

Ademais, outros fatores também afetam o valor do frete. Greves, eficiência do porto exportador, disponibilidade de armazenagem, não uso da intermodalidade, sazonalidade, carga de retorno, especificidades da carga e do veículo, prazo e tempo de entrega, pedágios e fiscalização, falta de ferrovias no território e infraestrutura inadequada provocam a instabilidade e flutuação do valor dos fretes agrícolas ao longo do ano (CORRÊA JUNIOR; CAIXETA FILHO, 2003; MARTINS, 2008; CAIXETA FILHO; MARTINS, 2011; CANGUSSU; ROSA; FIGUEIREDO, 2013). Corrêa Junior e Caixeta Filho (2002), Cangussu, Rosa e Figueiredo (2013) e Martins (2008) identificaram, ainda, que a distância percorrida foi o principal fator de influência do preço do frete.

Adicionalmente, Gameiro e Caixeta Filho (2010) complementam que, além dos produtos agroindustriais apresentarem baixo valor agregado, as regiões produtoras são distantes das regiões consumidoras. Existe aumento na demanda pelo serviço de transporte em determinadas épocas do ano devido à sazonalidade dos produtos agrícolas que são escoados logo após a colheita e à oscilação significativa nos preços dos fretes agrícolas. Caixeta Filho e Gameiro (2001) explicam que a intensa utilização dos serviços de transportes no escoamento de soja em períodos de safra causa forte desestabilização no mercado de fretes rodoviários no Brasil.

Oliveira, Cicolin e Santos (2014) observaram o mesmo fenômeno. De acordo com os autores, o mercado de fretes de soja sofre desestabilização devido ao aumento de oferta de grãos no período das safras. Com necessidade de escoamento rápido do 


\section{REVISTA ENIAC PESQUISA}

produto, devido à falta de espaço para armazenar em condições adequadas o produto (FILIPPI, 2017), bem como concorrência com outros produtos agrícolas, o preço do frete fica instável (SOARES; CAIXETA FILHO, 1997).

Soares e Caixeta Filho (1997) relatam que esse fenômeno ocorre com o mercado de fretes, pois ele é extremamente competitivo e o preço é determinado por interações relativas à demanda, à oferta e ao ambiente. Assim, em momentos de rush no sistema de transporte, como no auge de escoamento de soja, milho e açúcar, em meados dos meses de março e junho, ocorre o racionamento da oferta de caminhões, e dessa forma, o valor do frete sofre influência, com flutuações instáveis (SOARES; CAIXETA FILHO, 1997).

Oliveira (2014) descreve que, se não houvesse déficit de armazenamento e houvesse armazéns na própria propriedade para esses produtos em períodos de pico de safra, não ocorreria rush de vendas e problemas subsequentes poderiam ser evitados, como o congestionamento nos portos durante o escoamento da produção.

Portanto, existe uma logística de distribuição para o Agronegócio da soja ineficiente e com inúmeros entraves logísticos que comprometem o escoamento da produção e interferem no custo do transporte e logístico e refletem no custo final do produto.

\section{MATERIAIS E TÉCNICAS}

Essa pesquisa é classificada como aplicada, pois gera conhecimentos com aplicação prática; quantitativa, uma vez que traduz em números opiniões e informações e faz uso de técnicas estatísticas; e descritiva, porque possibilita estabelecimento de relações entre variáveis (SILVA; MENEZES, 2001).

Para alcançar o objetivo do trabalho, foram utilizados dados de: (i) frete de soja, fornecidos pelo Instituto Matogrossense de Economia Aplicada (IMEA); e (ii) preços do óleo diesel, fornecidos pela Agência Nacional do Petróleo, Gás Natural e Biocombustíveis (ANP). Os valores dos fretes de soja são relativos à rota de origem Sorriso/MT e destino porto de Santos/SP, respectivamente, o principal estado produtor e o principal porto destino para exportação de soja. Ambos os valores, fretes de soja e preço diesel, são valores diários compreendidos no período de janeiro de 2015 a maio de 2018 . 
A partir dos dados, foi determinada e analisada a relação entre as variáveis a partir do Diagrama de Dispersão, Correlação e Regressão Linear. Triola (2017) descreve que os Diagramas de Dispersão são gráficos de pares de dados quantitativos ( $x$, $y$; sendo $x$ o eixo horizontal e variável independente, e $y$ o eixo vertical e variável dependente), que objetivam determinar a existência de correlação (relação), ou não, entre duas variáveis. Para Antonio e Carvalho (2007), o Diagrama de Dispersão facilita observar algum tipo de relacionamento entre duas variáveis. Caso os valores de $x$ e $y$ cresçam, existe uma correlação positiva. Caso os valores de $x$ cresçam e os valores de $y$ decresçam, haverá uma correlação negativa (TRIOLA, 2017). Nesse estudo, a variável dependente (consequência) é o frete de soja (eixo y) e a variável independente (causa) é o preço do óleo diesel (eixo x).

Quanto à Regressão Linear e Correlação, Antonio e Carvalho (2007), que analisaram a influência entre frete rodoviário de fertilizante e volume de açúcar, relatam que esse método é o mais apropriado para esse caso, já que é possível verificar se existe correlação confiável entre as variáveis. Assim, numa correlação, é possível determinar o Coeficiente de Correlação (r) que evidencia numericamente "quão bem dados amostrais emparelhados se ajustam ao padrão de uma reta" (TRIOLA, p. 492, 2017); e, numa Regressão, é possível determinar a relação e a dependência entre $y$ e $x$ (SARTORIS, 2013).

Assim, na análise de uma correlação, é possível medir a força de associação entre variáveis numéricas, e a análise de uma regressão objetiva prever valores de uma variável dependente em função de uma variável independente por meio de modelos estatísticos (LEVINE; BERENSON; STEPHAN, 1998).

Ademais, nesse estudo, foi utilizado o coeficiente de correlação linear de Pearson, o qual varia entre -1 e $1(-1 \leq r \leq 1)$, em que valores próximos de zero indicam baixa correlação; valores iguais a zero indicam nenhum relacionamento entre as variáveis; e, valores próximos a -1 ou 1 indicam alta influência entre as variáveis, em que, -1 indica uma correlação perfeita negativa e 1 indica uma correlação perfeita positiva (SARTORIS, 2013; TRIOLA, 2017).

Callegari-Jacques (2003) avaliam ainda que o coeficiente de correlação pode ser interpretado como: (i) correlação nula $(r=0)$; (ii) correlação fraca $(0<|r|<0,3)$; (iii) 


\section{REVISTA ENIAC PESQUISA}

correlação moderada $(0,3 \leq|r|<0,6)$; (iv) correlação forte $(0,6 \leq|r|<0,9)$; correlação muito forte $(0,9 \leq|r|<1)$; e, (vi) correlação perfeita $(|r|=1)$.

Posteriormente, é possível descrever algebricamente tal resultado por meio de uma equação ou reta de regressão, a qual é dada por:

$$
Y=\alpha+b X+e
$$

Onde:

$Y$ é a variável dependente, no caso o FRETESOJA;

$a$ é o valor constante em que toca o eixo $X$;

$b$ é o coeficiente angular que multiplica a variável independente $X$;

$X$ é a variável independente, no caso o PREÇODIESEL;

$e$ é o erro aleatório.

Por fim, para gerar os resultados estatísticos com os dados do estudo, foi utilizado o software IBM SPSS Statistics 22 e realizado o teste de Durbin-Watson, para verificar erros independentes em uma escala entre 0 e 4 . Observa-se que valor 2 indica que os resíduos não são correlacionados, por sua vez, menor que 2 indica correlação positiva e maior que 2 indica correlação negativa (FIELD, 2009).

\section{RESULTADOS E DISCUSSÃO}

\subsection{EVOLUÇÃO DOS PREÇOS: FRETE DE SOJA E PREÇO DIESEL}

A Figura 1 e Figura 2 apresentam a evolução da série de dados para preços de frete de soja e óleo diesel dessa pesquisa no período de janeiro de 2015 a maio de 2018. É possível observar aumento nos valores dos preços do diesel em todo período e variação entre os valores dos fretes de soja.

Figura 1- Evolução dos valores de frete de soja no período de janeiro de 2015 a maio de 2018.

Revista ENIAC Pesquisa, Guarulhos (SP), V.8, n.2, jul.- dez. 2019. 
Pest

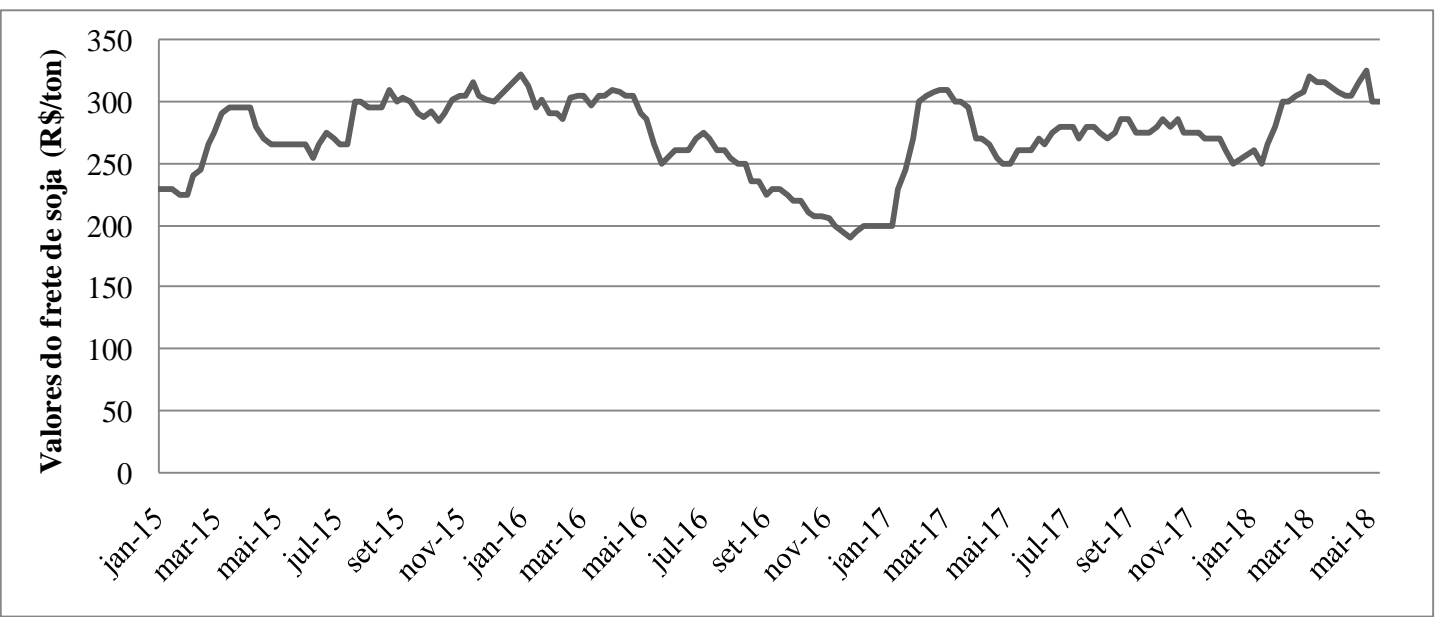

Fonte: Elaboração própria a partir dos dados do IMEA (2018).

De acordo com a Figura 1 visualiza-se que, em períodos de picos de safra de soja, principalmente os meses de fevereiro e março, há aumento nos valores dos fretes da commodity. Tal aumento reflete o aumento da oferta da commodity no mercado após sua colheita e, consequentemente, a insuficiência do serviço de transporte para distribuir o produto, principalmente via modal rodoviário, o que gera a instabilidade dos valores de fretes para o período. Gameiro e Caixeta Filho (2010) e Oliveira, Cicolin e Santos (2014), em suas pesquisas, também encontraram os mesmos resultados para períodos anteriores.

Além disso, Soares e Caixeta Filho (1997) explicam que esse fenômeno ocorre devido às interações de demanda, oferta e ambiente. Dessa forma, o serviço de transporte existente no mercado não suportará o aumento da oferta do produto soja nos meses de safra, o que causará a flutuação nos valores do frete e seu aumento devido à competição do mercado.

Atrelada a esse fator, a concorrência com outros produtos agrícolas, como açúcar e milho, também influencia essa dinâmica, como também a necessidade de rápido escoamento da produção logo após a colheita devido à indisponibilidade de locais para a armazenagem e sua possível comercialização em períodos de entressafra, quando seria possível obter-se um ganho a mais pelo preço do produto devido à sua escassez no mercado, isto é, sua comercialização estratégica.

A Figura 2 apresenta a evolução do preço do diesel para o período do estudo.

Revista ENIAC Pesquisa, Guarulhos (SP), V.8, n.2, jul.- dez. 2019. 
Figura 2- Evolução dos valores do preço Diesel no período de janeiro de 2015 a maio de 2018.

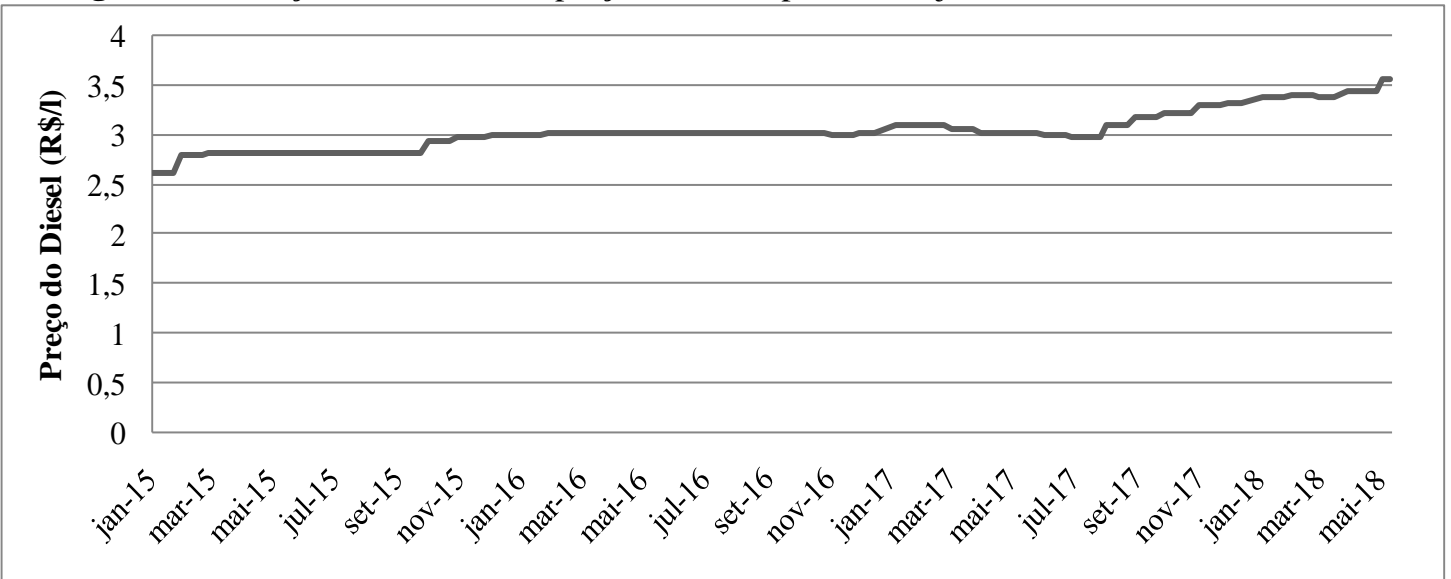

Fonte: Elaboração própria a partir dos dados da ANP (2018).

Nota-se que o valor médio do preço do diesel aumenta para o período de estudo. Isso ocorre devido a alguns fatores na conjuntura político-econômica nacional e internacional, como aumento dos preços internacionais do petróleo, devido à desvalorização do Real em relação ao dólar, os quais são repassados ao consumidor. Além dos fatores acima explicados para a instabilidade do preço de frete de soja, o aumento ou redução no valor do preço do diesel também provoca mudanças nos valores do frete.

\subsection{DIAGRAM]A DE DISPERSÃO, CORRELAÇÃO E REGRESSÃO}

A seguir, são apresentados os resultados do Gráfico de Dispersão, Correlação e Regressão a respeito das variáveis frete de soja e preço do óleo diesel.

Revista ENIAC Pesquisa, Guarulhos (SP), V.8, n.2, jul.- dez. 2019. 


\section{REVISTA ENIAC PESQUISA}

Figura 3 - Dispersão dos valores de frete de soja ( $\mathrm{R} \$ /$ ton) e preço do diesel ( $\mathrm{R} \$ / \mathrm{l})$.

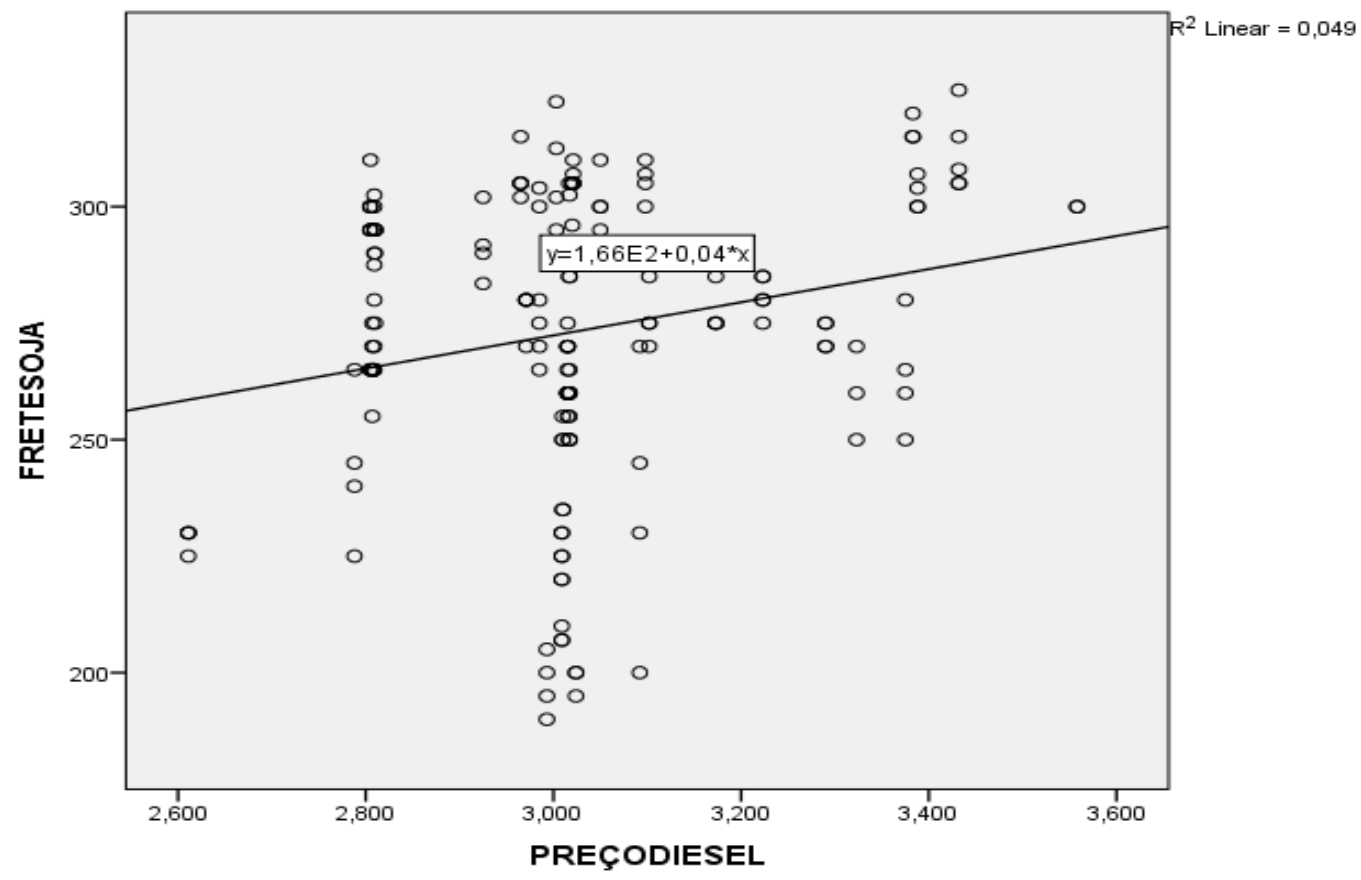

Fonte: Elaborado pelos autores (2018).

De acordo com o Gráfico de Dispersão, é possível perceber que existe relação linear crescente e positiva entre a variável independente preço do diesel $(x)$ e a variável dependente frete de soja (y). À medida que o valor do preço do óleo diesel aumenta, o valor do preço do frete de soja também aumenta.

Além disso, nota-se que, como a relação linear entre as variáveis preço do diesel e frete de soja são discretas, possivelmente outros fatores também afetam o frete de soja, como greves, distância origem/destino, disponibilidade de armazenagem, porto exportador, gastos com combustíveis, sazonalidade, carga de retorno etc.. Antonio e Carvalho (2007) também encontraram resultados semelhantes ao analisar a dispersão entre preço do frete de fertilizante e volume de exportação de açúcar no Porto de Santos. Os autores ainda relataram que os pontos que se distanciam da linha normal são mais influenciados por outros fatores, isto é, por uma terceira variável.

Dessa forma, existe relação linear entre as variáveis preço do diesel e frete de soja, mas poucos valores de frete de soja para o período do estudo são afetados pelo preço do diesel, os quais se concentram próximos da linha normal, portanto, seria necessário complementar essa interpretação com a incorporação de outras variáveis de análise para o mesmo período. 


\section{REVISTA ENIAC PESQUISA}

Ademais, a Tabela 2 apresenta as correlações entre as variáveis frete de soja e preço do óleo diesel.

Tabela 2 - Correlação entre os preços do óleo diesel e frete de soja.

\begin{tabular}{llrrr} 
& & FRETESOJA & PREÇODIESEL \\
\hline \multirow{2}{*}{ FRETESOJA } & \multicolumn{2}{l}{ Correlação de Pearson } & 1 &, $221^{* *}$ \\
\cline { 2 - 4 } & Sig. (2 extremidades) & &, 004 \\
\cline { 2 - 4 } & $\mathrm{N}$ & 169 & 169 \\
\hline PREÇODIESEL & Correlação de Pearson &, $221^{* *}$ & 1 \\
\cline { 2 - 4 } & Sig. (2 extremidades) &, 004 & 169 \\
\cline { 2 - 4 } & $\mathrm{N}$ & 169 & \\
\cline { 2 - 4 } & &
\end{tabular}

Fonte: Elaborado pelos autores (2018).

** A correlação é significativa ao nível de 0,01 ( 2 extremidades).

A Tabela 2 evidencia o coeficiente de correlação linear entre frete de soja e preço do óleo diesel, o qual é 0,221 ou $22,1 \%$, portanto, evidencia correlação entre os fatores. De acordo com a classificação qualitativa de Callegari-Jacques (2003) sobre o coeficiente de correlação, esse resultado indica correlação fraca entre as variáveis frete de soja e preço do óleo diesel $(\mathrm{r}=0,221)$. Dessa forma, as alterações no preço dos combustíveis, no caso do óleo diesel, não impactam tanto no preço do frete de soja.

A Tabela 3, por sua vez, apresenta os coeficientes de correlação e as constantes, com o qual é possível determinar a equação de regressão das variáveis do estudo.

Tabela 3 - Coeficientes entre os preços do óleo diesel e frete de soja(a).

\begin{tabular}{|c|c|c|c|c|c|}
\hline \multirow[b]{2}{*}{ Modelo } & \multicolumn{2}{|c|}{$\begin{array}{l}\text { Coeficientes não } \\
\text { padronizados }\end{array}$} & \multirow{2}{*}{$\begin{array}{c}\begin{array}{c}\text { Coeficientes } \\
\text { padronizados }\end{array} \\
\text { Beta }\end{array}$} & \multirow[t]{2}{*}{$\mathrm{T}$} & \multirow[t]{2}{*}{ Sig } \\
\hline & $\mathrm{B}$ & Erro Padrão & & & \\
\hline 1 (Constante) & 165,753 & 36,740 & & 4,511 &, 000 \\
\hline PREÇODIESEL &, 036 &, 012 & ,221 & 2,934 & ,004 \\
\hline
\end{tabular}

Fonte: Elaborado pelos autores (2018). a. variável dependente FRETESOJA.

A partir dos coeficientes obtidos, foi possível encontrar a equação de regressão linear que prevê a variável dependente. Dessa forma, a equação $Y=a+b X$ pode ser escrita como FRETESOJA = 165,753 + 0,036.PREÇODIESEL, onde $Y$ é a variável dependente, no caso FRETESOJA; $X$ é a variável independente, no caso PREÇODIESEL; $a$ é o valor constante em que toca o eixo $Y$; e $b$ é o coeficiente angular que multiplica a variável independente $X$.

Por fim, a Tabela 4 apresenta o resumo do modelo.

$\mathrm{O}$ coeficiente de determinação $\mathrm{R}^{2}$, apresentado na Tabela 4 , mede a proporção da variação que é explicada pela variável independente no modelo de regressão. Assim, 
$4,9 \%\left(r^{2}=0,049\right)$ da variação no frete de soja podem ser explicados pela variabilidade no preço do óleo diesel. Em outras palavras, o preço do óleo diesel pode explicar em até $4,9 \%$ o preço do valor do frete de soja, valor considerado baixo.

Tabela 4 - Resumo do modelo gerado (b).

\begin{tabular}{rrrrrr}
\hline & & & R quadrado & Erro padrão da & Durbin- \\
Modelo & $\mathrm{R}$ & R quadrado & ajustado & estimativa & Watson \\
1 &, $221_{\mathrm{a}}$ &, 049 &, 043 & 30,079 &, 096 \\
\hline
\end{tabular}

Fonte: Elaborado pelos autores (2018). a. Preditores: (Constante). PREÇODIESEL. b. variável dependente: FRETESOJA.

Por fim, o teste de Durbin-Watson resultou em 0,096 para verificação de erros independentes. Isso significa que 0,096 é menor que 2 , o que indica correlação positiva (FIELD, 2009).

\section{CONSIDERAÇÕES FINAIS}

Com o objetivo de analisar as relações entre os preços de fretes de soja e preços do óleo diesel para da cidade de Sorriso/MT até o porto de Santos, no período de janeiro de 2015 a maio de 2018, foi possível constatar que existe baixa correlação linear positiva entre as variáveis. Assim, os preços de combustível, no caso do óleo diesel, apresentam relação com os fretes de soja, mas essa relação é baixa.

Conclui-se, então, que existem inúmeras variáveis que influenciam o valor do frete de soja, e o preço do óleo diesel é uma delas.

Ademais, apenas os valores do óleo diesel não explicam em sua totalidade as variações no preço do frete de soja para o período do estudo. O entendimento completo desse comportamento necessita analisar mais variáveis que afetam o valor do frete, como greves, distância origem/destino, disponibilidade de armazenagem, porto exportador, gastos com combustíveis, sazonalidade, carga de retorno etc., como também, incorporar amostras maiores que expressam maior conformidade com a realidade.

Com o intuito de aprofundar esse estudo, sugerem-se como trabalhos futuros: (i) analisar os fatores que interferem nos fretes de soja com outras variáveis incorporadas no modelo, como distância, diferentes portos exportadores, rotas com intermodalidade, decisão de armazenar a produção e carga de retorno; e, (ii) analisar a influência que os fatores que afetam o frete de soja com origem em Sorriso/MT geram ao considerar 
diferentes destinos exportadores, no caso, escoamento pelo Arco-Norte versus portos da região Sudeste e Sul, os quais estão saturados.

\section{REFERÊNCIAS}

ANTONIO, J.P.G.R.; CARVALHO, L.B. A Influência da exportação de açúcar no porto de santos sobre o frete rodoviário do fertilizante no estado de São Paulo. Revista de Economia e Agronegócio, v.5, n.2, p. 279-300, 2007.

BALLOU, R.H. Logística Empresarial: Transportes, Administração de Materiais e Distribuição Física. 2. ed. São Paulo: Atlas, 2011.

CAIXETA FILHO, J.; MARTINS, R. Gestão logística do transporte de cargas, São Paulo: Atlas, 2011.

CAIXETA FILHO, J. V.; GAMEIRO, A. H. (Org.). Transporte e logística em sistemas agroindustriais. São Paulo: Editora Atlas, 2001.

CALLEGARI-JACQUES, S.M. Bioestatística - Princípios e Aplicações. Porto Alegre: Artmed, 2003.

CANGUSSU, S.V.; ROSA, M.J.A.; FIGUEIREDO, A.M.R. Determinantes do preço do frete rodoviário para transporte de soja em grãos em Mato Grosso. Revista de Economia, Anápolis-GO, v. 9, n.1, p. 78-94, jan./jun. 2013.

CASTILLO, R. Transporte e logística de granéis sólidos agrícolas: componentes estruturais do novo sistema de movimentos do território brasileiro. Investigaciones Geográficas, v. 55, p. 79-96, 2004.

CNT - Confederação Nacional do Transporte. Boletim Estatístico, janeiro de 2018. Disponível em: <http://www.cnt.org.br/Boletim/boletim-estatistico-cnt>. Acesso em maio de 2018.

CONAB - COMPANHIA NACIONAL DE ABASTECIMENTO. Safra Brasileira de Grãos, 2018. Disponível em: < https://www.conab.gov.br/info-agro/safras/graos>. Acesso em maio de 2018.

CORREA, V.H.C.; RAMOS, P. A Precariedade do Transporte Rodoviário Brasileiro para o Escoamento da Produção de Soja do Centro-Oeste: situação e perspectivas. Revista de Economia e Sociologia Rural, Brasília, v. 48, n.2, p. 447-472, abr./jun. 2010.

CORRÊA JUNIOR, G.; CAIXETA FILHO, J.V. Principais determinantes do preço do frete rodoviário para o transporte de soja em grãos em diferentes estados brasileiros: uma análise econométrica. Economia Aplicada, v.7, n. 1, 2003. 
COTRIM, N.Q.S.; MACHADO, G.R. Logística de Distribuição: um estudo do nível de serviço logístico em uma multinacional líder no segmento de produtos lácteos frescos (PLF). Enciclopédia Biosfera, Centro Científico Conhecer, Goiânia, v.07, n.12, p.120, 2011.

FIELD, A. Descobrindo a Estatística usando o SPSS. $2^{\mathrm{a}}$ edição, Porto Alegre: Artmed, 2009.

FILIPPI, A.C.G.; GUARNIERI, P.; FARIAS, J.S. Logística agroindustrial: uma revisão sistemática nos anais de Congresso da SOBER. Revista em Agronegócio e Meio Ambiente, v. 10, n. 4, p. 1077-1112, out./dez. 2017.

GABAN, A.C.; MORELlI, F.; BRISOLA, M.V.; GUARNIERI, P. Evolução da produção de grãos e armazenagem: perspectivas do Agronegócio Brasileiro para 2024/25. InformeGepec, Toledo, v. 21, n.1, p. 28-47, jan./jun. 2017.

GAMEIRO, A.H.; CAIXETA FILHO, J.V. Índice de preço para o transporte de cargas: o caso da soja. Nova Economia, Belo Horizonte, v. 20, n.1, p. 121-163, jan/abril de 2010 .

IMEA - INSTITUTO MATOGROSSENSE DE ECONOMIA APLICADA, Série de preços de frete de soja, 2018.

LEVINE, D.M.; BERENSON, M. L.; STEPHAN, D. Estatística: teoria e aplicações usando Microsoft Excel em português. Rio de Janeiro: LTC, 1998.

MARTINS, R.S. Estudo da formação do frete rodoviário e potencial de conflitos em negociações em cadeias do Agronegócio Brasileiro. Organizações Rurais \& Agroindustriais, Lavras, v. 10, n. 1, p. 73-87, 2008.

MARTINS, R.S.; LOBO, D.S.; ALVES, A.F.; SPROESSER, R.L. Fatores relevantes na contratação de serviços em terminais intermodais para granéis agrícolas. Revista de Economia e Sociologia Rural, Brasília, v. 52, n. 2, p. 347-364, abril/junho 2014.

MDIC - Ministério da Indústria, Comércio Exterior e Serviços. Maio/2018. Série histórica: 1998 a 2018 - Balança Comercial Brasileira. Disponível em: <http://www.mdic.gov.br/component/content/article?id=84>. Acesso em maio de 2018.

MORALES, P.R.G.D.; D’AGOSTO, M.A.; SOUZA, C.D.R. Otimização de rede intermodal para o transporte de soja do norte do Mato Grosso ao porto de Santarém. Journal of Transport Literature, v. 7, n. 2, p. 29-51, Apr. 2013.

OLIVEIRA, A.L.R. A Logística agroindustrial frente aos mercados diferenciados: principais implicações para a cadeia da soja. Informações Econômicas, SP, v. 41, n. 6 , jun. 2011.

OLIVEIRA, A. L. R. A logística do agronegócio: para além do apagão logístico. In: A. M. Buainain, E. Alves, J. M. F. J. Silveira, \& Z. Navarro (Orgs.). O mundo rural no 


\section{REVISTA ENIAC PESQUISA}

Brasil do século 21: a formação de um novo padrão agrário e agrícola, Brasília: Embrapa, p. 337-370, 2014.

OLIVEIRA, A.L.R.; CICOLIN, L.; SANTOS, M.C. Estimativa do custo rodoviário da soja: uma análise da rota Sorriso-Santos. Revista de Economia e Agronegócio, v.11, n. 2,2014 .

RESENDE, E.S.; BONJOUR, S.C.M.; FIGUEIREDO, A.M.R. Análise de rotas alternativas de transporte: o caso da soja de Mato Grosso. Revista de Estudos Sociais, ano 9, n.1 e 2, 2007.

SILVA, Igor Pereira et al. Minimização dos custos de frete na distribuição de cimento por programação linear. Revista Eniac Pesquisa, v. 7, n. 1, p. 97-108, 2018.

SILVA, E.L.; MENEZES, E.M. Metodologia da Pesquisa e Elaboração de Dissertação. $3^{\text {a }}$ edição revisada e atualizada. Florianópolis, 2001. 121 p.

SOARES, M.G.; CAIXETA FILHO, J.V. Caracterização do mercado de fretes rodoviários para produtos agrícolas. Revista Gestão e Produção, v.4, n.2, p. 186-204, ago. 1997.

TRIOLA, M.F. Introdução à Estatística. 12ª edição, Rio de Janeiro: LTC, 2017.

Revista ENIAC Pesquisa, Guarulhos (SP), V.8, n.2, jul.- dez. 2019. 